\title{
ANÁLISES QUÍMICAS, FÍSICAS E MINERALÓGICAS DE SOLO EM DISTINTOS SISTEMAS NA REGIÃO DA TOCA DA ONÇA, DISTRITO DE LUMIAR - NOVA FRIBURGO/RJ
}

\author{
Bruno de Souza Mattos ${ }^{(1)}$, Ana Valéria Freire Allemão Bertolino ${ }^{(2)}$, Luiz Carlos Bertolino ${ }^{(3)}$ \\ (1) Departamento de Geografia/FFP/UERJ, E-mail: brunomattos_geo@ @otmail.com \\ (2) Departamento de Geografia/FFP/UERJ, E-mail: anabertolino@uol.com.br \\ ${ }^{(3)}$ Departamento de Geografia/FFP/UERJ, E-mail: lcbertolino@uol.com.br
}

\section{Eixo: SOLOS E PAISAGENS}

\begin{abstract}
Resumo
No distrito de Lumiar - Nova Friburgo/RJ, técnicas agrícolas tradicionais como o pousio, ou relativamente recentes como os Sistemas Agroflorestais (SAF) são usadas como forma minimizar os impactos da agricultura sobre o solo, buscando sua melhor conservação. O objetivo geral deste estudo é determinar a composição química, física e mineralógica das camadas superficiais do solo em distintos sistemas (Pousio, Sistema Agroflorestal, Pasto e Floresta), tendo sido coletadas amostras de solo nas profundidades $0-5$ e $5-10 \mathrm{~cm}$. A classificação textural do solo em todos os sistemas encontra-se na classe franco-arenosa, com exceção do solo do pasto, classificado como franco-argilo-arenoso. A densidade aparente evidencia que o solo do Pasto é o mais compactado com valor próximo a $1,3 \mathrm{~g} / \mathrm{cm}^{3}$. No Sistema Agrofloresta foram encontrados os maiores valores de macroporosidade no solo (25\%). Neste sistema a mineralogia da fração argila é composta basicamente por caulinita, haloisita, montimorilonita, ilita e gibbsita.
\end{abstract}

Palavras chave: Sistema Agroflorestal, manejo, propriedades do solo, conservação.

\section{Introdução}

O município de Nova Friburgo está inserido na franja verde do estado do Rio de Janeiro, fazendo com que se torne um lugar de grande interesse para estudos relacionados às propriedades do solo, ainda mais o distrito de Lumiar, que se encontra dentro da Área de Proteção Ambiental (APA) do Macaé de Cima, território definido por lei como área destinada à conservação de processos naturais, adequando as várias atividades humanas às características ambientais da área (BRASIL, 1981).

Nos últimos 200 anos de uso e ocupação da região, a principal atividade econômica está relacionada à agricultura familiar. Todavia, as áreas de pastagem ocupam 6,4\% da APA, e coexistem como uma forma encontrada pelos agricultores de evitar a perda de suas terras. Já que os lugares onde as árvores ultrapassam $5 \mathrm{~cm}$ de diâmetro de tronco podem ser considerados pela legislação como áreas intocáveis e de preservação (INEA, 2010). De acordo com Bertolino e Bertolino (2010), o mesmo motivo vem fazendo com que o tempo de Pousio que no passado chegava até a 12 anos, seja regredido para no máximo 3 anos. 
O termo agrofloresta está ligado às práticas agrícolas que tem intenção de recuperar ou manter a cobertura vegetal de uma área usada para a agricultura (GLIESSMAN, 2001). A produção de uma agrofloresta ocorre quando se inicia a recuperação do solo degradado buscando uma sucessão natural, até alcançar as características similares a de uma Floresta, entretanto, implantando espécies de cultivo agrícola. Esta se baseia no desenvolvimento de estágios sucessivos de recuperação do ambiente florestal, buscando sempre utilizar espécies nativas adequadas para cada finalidade (CANDIOTTO et al, 2008).

Enquanto técnica de cultivo, o manejo de solo pode ser compreendido como operações que buscam manter a alta produtividade do solo, reter o máximo de água da chuva possível, incrementar a infiltração, reduzir os processos erosivos e de lixiviação, evitar a perda de nutrientes e proporcionar boas condições físicoquímicas para as culturas (MIRANDA, 2004). Os solos cultivados devem ser preparados a fim de que ocorra o mínimo de alterações possíveis em suas características físicas e químicas (CASTRO et al., 1986).

Entender os processos relacionados à dinâmica do terreno é de suma importância para adoção de medidas efetivas de controle preventivo e corretivo. O solo faz parte de um sistema que está integrado a fatores naturais e antrópicos (SALOMÃO, 2010). Assim, se faz necessária a adoção de manejos menos nocivos a sua estrutura. Estudos sobre a geomorfologia de encostas realizados a partir de parcelas hidroerosivas do tipo Gerlach nos mesmos sistemas mostraram que o processo de escoamento superficial é mais intenso no Pasto, enquanto no Sistema Agroflorestal e na Floresta a água possui maior potencial de infiltração. Todavia, os maiores valores de perda de solo foram encontrados na Floresta, o que estaria relacionado às propriedades do solo (LESSA, 2013).

O estudo teve como objetivo compreender as diferenças nas propriedades químicas, físicas e mineralógicas das camadas superficiais do solo em quatro distintos sistemas (Pousio, Sistema Agroflorestal, Pasto e Floresta) localizados todos em uma mesma vertente com declividade de aproximadamente $30^{\circ}$ no sítio Abaetetuba, situado no distrito de Lumiar - Nova Friburgo / RJ, de modo a analisar como a cobertura vegetal e o uso do solo podem interferir não só nas propriedades pedológicas, como também nas transformações das paisagens.

\section{2 - Área de Estudo}

A área de estudo localiza-se no Sítio Abaetetuba, Toca da Onça, Lumiar, $5^{\circ}$ distrito de Nova Friburgo-RJ. Estando contida na sub-bacia do Córrego das Paineiras, inserida na bacia hidrográfica do Rio Bonito que faz parte da Área de Proteção Ambiental (APA) de Macaé de Cima, localizada na região serrana do Estado do Rio de Janeiro (Figura 1). 
XVII Simpósio Brasileiro de Geografia Fisica Aplicada

I Congresso Nacional de Geografia Física
OS DESAFIOS DA GEOGRAFIA FÍSICA NA FRONTEIRA DO CONHECIMENTO

Instituto de Geociências - Unicamp

Campinas - SP

28 de Junho à 02 de Julho de 2017

O município de Nova Friburgo localiza-se na Mesorregião Centro Fluminense e possui 182.082 habitantes distribuídos em uma área de 933,414 km² (IBGE, 2010). É de grande importância para a economia estadual por fazer parte da Franja Verde do Estado.

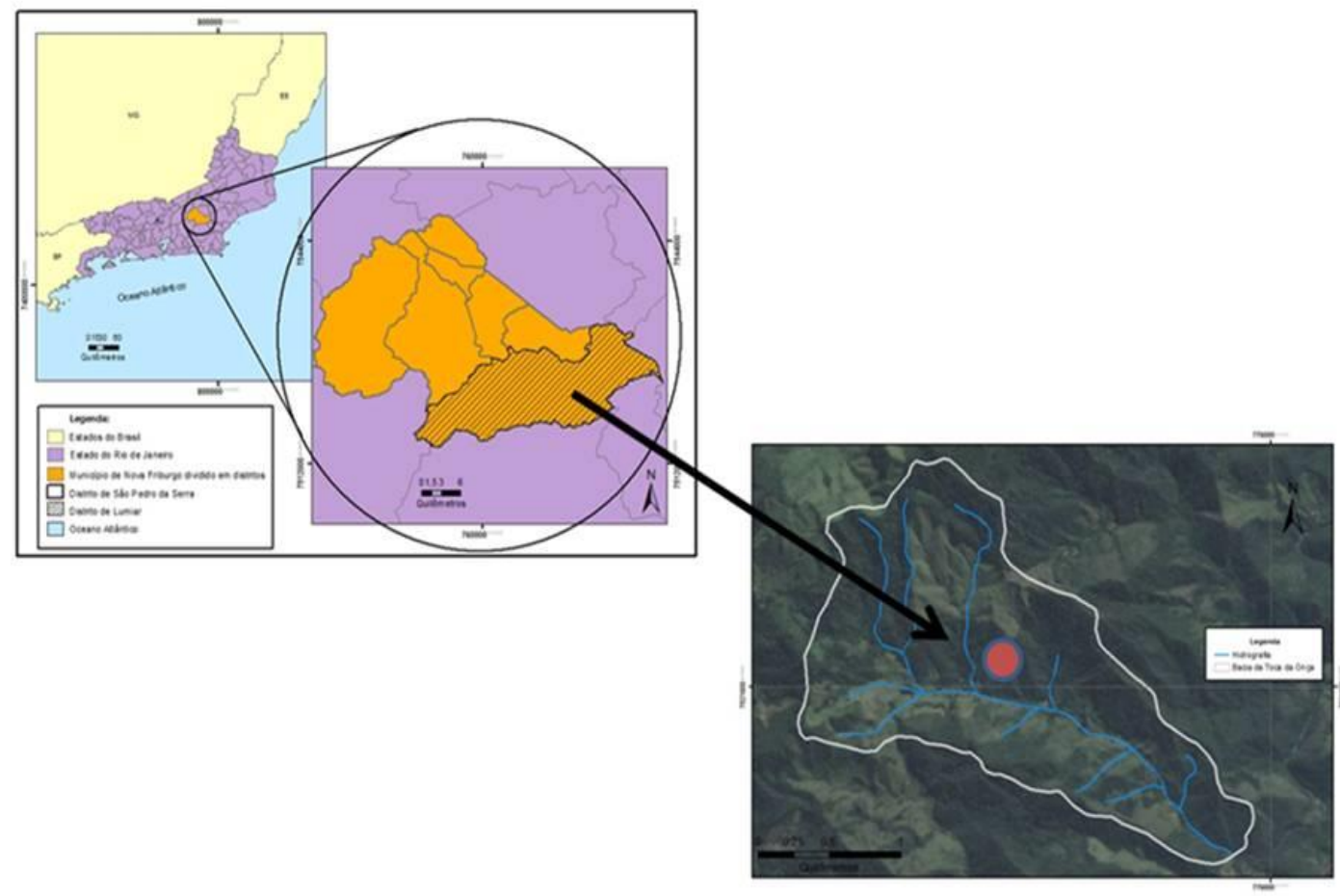

Figura 1: Localização da área de estudo.

O clima, segundo a classificação de Koppen, se aproxima ao mesotérmico brando Cfb, (sempre úmido com verão ameno). Os solos predominantes na área são os Cambisolos seguidos dos Latossolos VermelhoAmarelo e afloramentos de rocha (INEA, 2010).

Nova Friburgo está inserida no cinturão orogênico do Atlântico, uma faixa de complexidade litológica e estrutural, com predomínio de rochas metamórficas de diferentes tipos e idades, como gnaisses, migmatitos, quartzitos, micaxistos, filitos, assim como, de forma secundária, rochas intrusivas como o granito e o sienito, estando integrada ao Complexo Paraíba do Sul - Unidade São Fidélis (INEA, 2010). A geomorfologia da região apresenta predominantemente relevos pertencentes à classe Montanhosa, formada por terreno irregular e acidentado, localizada, em geral, no reverso da escarpa da Serra do Mar. Possui ainda vertentes rochosas com elevado declive, podendo apresentar mais de $1.500 \mathrm{~m}$, e vales encaixados formados a partir da erosão fluvial (DANTAS, 2000). 


\section{3 - Materiais e métodos}

Os dados foram obtidos a partir da realização de trabalho de campo, onde foi possível proceder à observação e descrição das paisagens e à coleta de amostras de solo que, posteriormente, foram analisadas no Laboratório de Geociências (LABGEO) da Universidade do Estado do Rio de Janeiro(UERJ) - Faculdade de Formação de Professores (FFP). Foram coletadas 15 amostras de solo deformado por ambiente a partir de trincheiras nas profundidades de 0 a 5 e 5 a 10 centímetros. Cada amostra possui aproximadamente 1,5 kg de solo. Após as 15 amostras serem despejadas em um reservatório e homogeneizadas, retirou-se e uma alíquota de $3 \mathrm{~kg}$ que foi levada para o Laboratório, onde o solo foi destorroado e deixado ao ar livre para a produção da terra fina seca ao ar (TFSA).

As análises granulométricas foram realizadas através do método da pipeta (EMBRAPA, 1997). Os dados de macroporosidade, microporosidade, porosidade total foram obtidos através do método da mesa de tensão, onde foi exercida sobre as amostras uma sucção equivalente a uma coluna de água de $60 \mathrm{~cm}$ (OLIVEIRA e PAULA, 1983). Já a análise de densidade aparente foi baseada no método do anel volumétrico proposto pela EMBRAPA (1999). Foram coletadas 5 amostras de cada uma das profundidades analisadas com o anel de Kopeck de $100 \mathrm{~cm}^{3}$.

$\mathrm{O}$ pH do solo foi obtido em água e $\mathrm{KCl}$, pelo método eletrométrico (EMBRAPA, 1999), com o auxilio do phmetro QUIMIS ${ }^{\circledR}$ pH Metro Microprocessado Q400MT. A determinação do carbono orgânico ocorreu a partir da metodologia de queima em meio ácido (EMBRAPA, 1999)

Os difratogramas de raios X (DRX) foram obtidos através da determinação do espaçamento interplanar a partir do método do pó utilizando um equipamento Bruker-D $4^{\circledR}$ Endeavor, nas seguintes condições de operação: radiação Co $\mathrm{K} \alpha(35 \mathrm{kV} / 40 \mathrm{~mA})$; velocidade do goniometro de $0,02^{\circ} 2 \theta$ por passo com tempo de contagem de 1 segundo por passo e coletados de 4 a $80^{\circ} 2 \theta$. As interpretações qualitativas dos espectros foram realizadas por comparação com padrões contidos no banco de dados PDF02 (ICDD, 2006) em software Bruker Diffrac Plus.

\section{4 - Resultados e Discussão.}

A análise granulométrica dos perfis do Pousio, SAF e Floresta revelam solos com grande quantidade de areia, sendo que o do Pousio é o que possui a maior proporção de areia. Na Floresta o solo apresenta maior quantidade de silte, 214,6 g/kg em 0-5 cm e 202,2 g/kg em 5-10 cm. Já o solo do Pasto caracteriza-se como o mais argiloso (Tabela I). Uma possível explicação para o solo mais argiloso no Pasto pode estar relacionada ao fato dos terracetes que se formaram a partir da compactação do solo com o pisoteio do gado 
no passado dificultarem que as partículas de argilas sejam transportadas para a baixa encosta através do escoamento superficial ou que as mesmas possam sofrer processo de iluviação.

Tabela I - Valores de areia, silte e argila ( $\mathrm{g} / \mathrm{kg}$ ) em distintos sistemas.

\begin{tabular}{cccccccc}
\hline & & \multicolumn{3}{c}{ GRANULOMETRIA (g/kg) } & & RELAÇ̃̃O \\
\hline SISTEMA & $\begin{array}{c}\text { PROFUNDIDADE } \\
(\mathrm{cm})\end{array}$ & $\begin{array}{c}\text { AREIA } \\
\text { GROSSA }\end{array}$ & $\begin{array}{c}\text { AREIA } \\
\text { FINA }\end{array}$ & AREIA & SILTE & ARGILA & $\begin{array}{c}\text { SILTE/ } \\
\text { ARGILA }\end{array}$ \\
\hline Floresta & $0-5$ & 440,3 & 189,1 & 629,4 & 214,6 & 156 & 1,38 \\
Pasto & $0-5$ & 383,7 & 222,9 & 606,6 & 163,4 & 230 & 0,71 \\
SAF & $0-5$ & 445,7 & 173,2 & 618,9 & 181,1 & 200 & 0,91 \\
Pousio & $0-5$ & 335,5 & 313,5 & 679 & 211 & 110 & 1,92 \\
& & & & & & & \\
Floresta & $5-10$ & 417 & 210 & 617,7 & 202,28 & 180 & 1,12 \\
Pasto & $5-10$ & 374,7 & 227,1 & 601,8 & 178,2 & 220 & 0,81 \\
SAF & $5-10$ & 439,8 & 174,7 & 614,5 & 193,5 & 192 & 1,01 \\
Pousio & $5-10$ & 396,3 & 314,3 & 711,5 & 170,5 & 118 & 1,44 \\
\hline
\end{tabular}

A grande quantidade de areia nos solos analisados, correlacionada com a porosidade total acima de $60 \%$ em todos os sistemas, com exceção do pasto, indica a alta suscetibilidade ao processo de lixiviação. Assim, deve-se haver extrema cautela na escolha do tipo de uso do solo, como por exemplo, no tipo de agricultura que será implantada. Opções inapropriadas podem levar ao esgotamento do solo.

A densidade aparente está relacionada com o grau de compactação do solo, e diretamente ligada aos valores de porosidade. O solo do Pasto apresenta a maior densidade aparente (Figura 2 A). Epstein e Grant apud Guerra (2010) afirmam que o aumento na densidade aparente pode ser responsável pelo inicio do processo erosivo. Em contrapartida o solo da Floresta possui o menor grau de compactação, o que aliado à alta quantidade da fração areia e ao grande percentual de macroporos, faz com que haja uma maior tendência à infiltração da água nesse solo.

$\mathrm{O}$ solo dos sistemas apresentam resultados similares de porosidade total em $0-5 \mathrm{~cm}$. Todavia, novamente quem destoa é o solo do Pasto, apresentando valores inferiores a 50\%. Em 5-10 cm o solo da Floresta é o que apresenta maior percentual de poros, com valores que se aproximam de 65\% (Figura 2 B). 

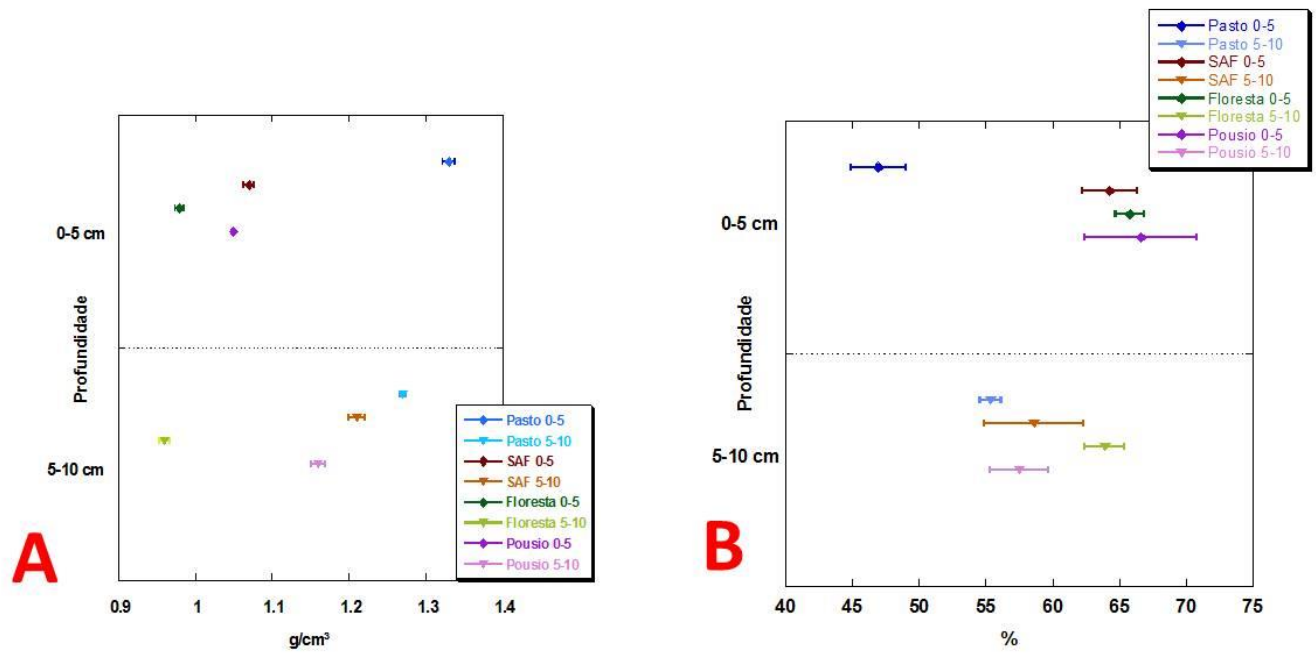

Figura 2 - Valores de densidade aparente (A) e porosidade total (B) em distintas profundidades e sistemas.

Nos primeiros $5 \mathrm{~cm}$ do solo o Pousio e a Floresta apresentam valores semelhantes de macroporos, superiores a 45\% (Figura 3 A). Entretanto, chama a atenção o fato do Pousio 5-10 cm apresentar maior percentual de macroporos, o que se explicaria pela grande quantidade de areia neste sistema. Todavia, o percentual de microporos no solo do Pousio em 5-10 cm é muito baixo, inferior a 10\%, assim como ocorre em ambas profundidades do Pasto. Já no SAF 0-5 cm, a microporosidade é superior a $25 \%$, sendo que reduzem para $20 \%$ em profundidade (Figura 3 B).
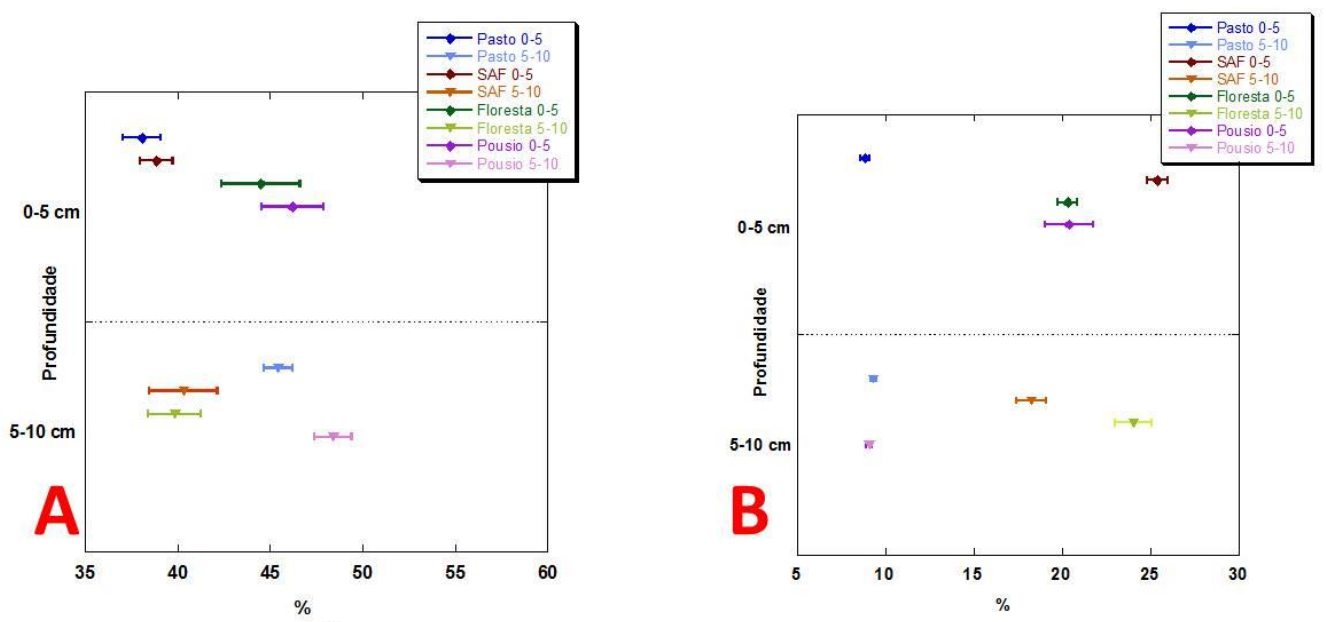

Figura 3- Valores de macroporosidade (A) e microporosidade (B) em distintas profundidades e sistemas.

A difratometria de raios X (DRX) realizada na fração argila mostra que há homogeneidade na ocorrência dos minerais tanto no que diz respeito às distintas profundidades, como aos diferentes sistemas. Nas 


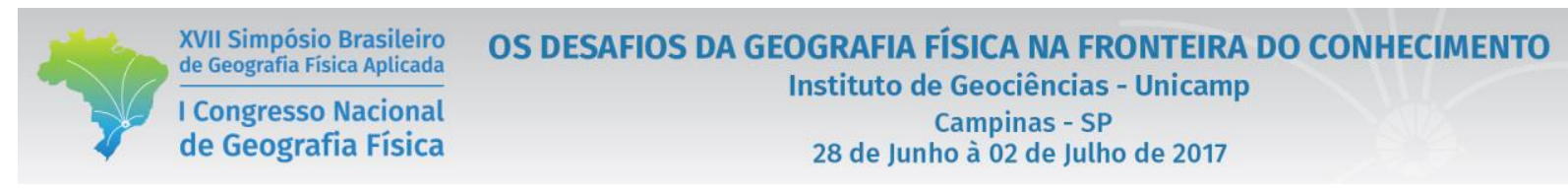

amostras de solo da fração argila foi encontrada ocorrência de caulinita, haloisita, montimorilonita, ilita e gibbsita (Tabela II) (Figuras 4 A e B). A caulinita, gibbsita e haloisita são minerais compostos por alumínio. O que, assim como estudos anteriores realizados nos mesmos sistemas por Gomes (2009), mostra que há grande quantidade de alumínio nos solos analisados já. O $\mathrm{Al}^{3}+$ é solúvel no solo, e tende a ser absorvido pela planta, dificultando que a mesma absorva outros nutrientes que são importantes para o seu desenvolvimento.

Tabela II - Composição mineralógica da fração argila nos solos dos ambientes estudados a partir do DRX.

\begin{tabular}{|c|c|c|}
\hline Sistema & $\begin{array}{l}\text { Profundidade } \\
\text { (cm) }\end{array}$ & Mineralogia \\
\hline Floresta & $0-5$ & $\begin{array}{l}\text { Caulinita, haloisita, montimorilonita, } \\
\text { ilita e gibbsita. }\end{array}$ \\
\hline Floresta & $5-10$ & $\begin{array}{l}\text { Caulinita, haloisita, montimorilonita, } \\
\text { ilita e gibbsita. }\end{array}$ \\
\hline Pousio & $0-5$ & $\begin{array}{l}\text { Caulinita, haloisita, montimorilonita, } \\
\text { ilita e gibbsita. }\end{array}$ \\
\hline Pousio & $5-10$ & $\begin{array}{l}\text { Ilita, caulinita, moscovita, quartzo, } \\
\text { montimorilonita e gibbsita }\end{array}$ \\
\hline SAF & $0-5$ & $\begin{array}{c}\text { Caulinita, haloisita, montimorilonita, } \\
\text { ilita e gibbsita. }\end{array}$ \\
\hline SAF & $5-10$ & $\begin{array}{c}\text { Caulinita, haloisita, montimorilonita, } \\
\text { ilita e gibbsita. }\end{array}$ \\
\hline Pasto & $0-5$ & $\begin{array}{c}\text { Montimorilonita, caulinita, haloisita, } \\
\text { quartzo e gibbsita }\end{array}$ \\
\hline Pasto & $5-10$ & $\begin{array}{l}\text { Caulinita, haloisita, montimorilonita, } \\
\text { ilita e gibbsita. }\end{array}$ \\
\hline
\end{tabular}
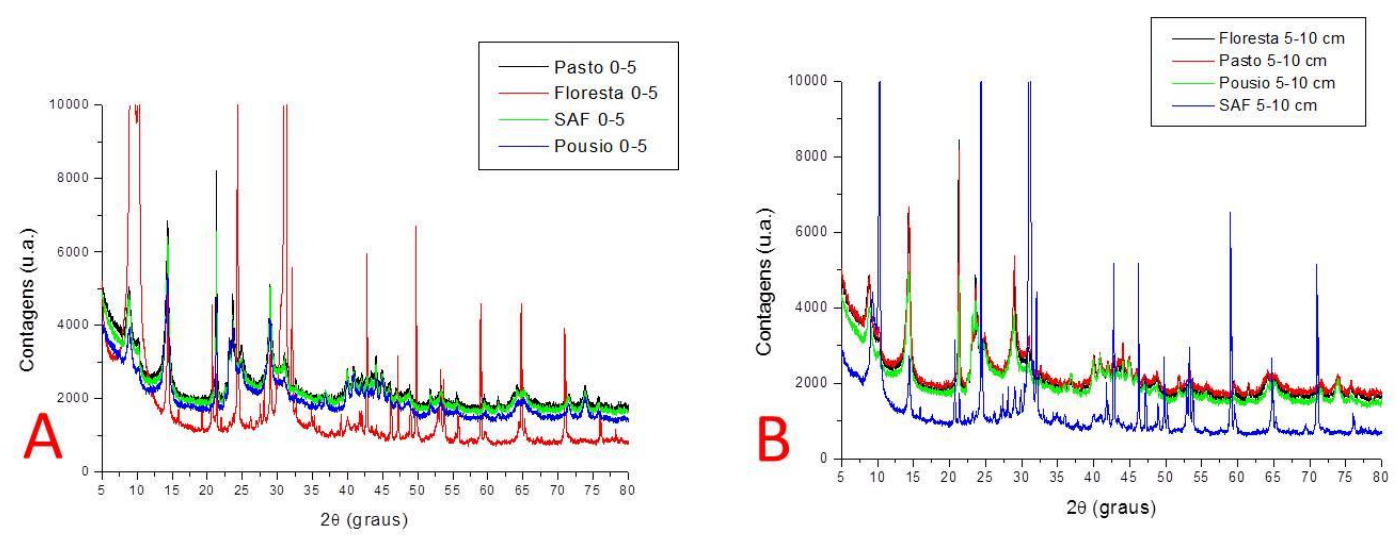

Figura 4 - Difratogramas de raios X da fração argila do solo em distintos sistemas em 0-5 cm (A) e 5-10 cm (B) Radiação Co Ka (35 kV/40 mA). 
Os dados de $\mathrm{pH}$ em mostram que os ambientem possuem acidez elevada nas distintas profundidades tanto na solução de $\mathrm{KCl}$ (Figura $5 \mathrm{~A}$ ), quanto na solução com água (Figura $5 \mathrm{~B}$ ). Na solução em $\mathrm{KCl}$, o Pousio em 0-5 cm e na Floresta em 5-10 cm apresentam a maior acides, com valor de pH igual a 3,4. Valor este semelhante ao da Floresta em 0-5 cm, onde o pH é de 3,5. Tais dados mostram que o acúmulo de matéria orgânica tende a influenciar no potencial de Hidrogênio dessas áreas. Já no pH em água, a maior acidez permanece na Floresta, sendo pH igual a 3,9 em 0-5 cm, e 3,8 em 5-10 cm.
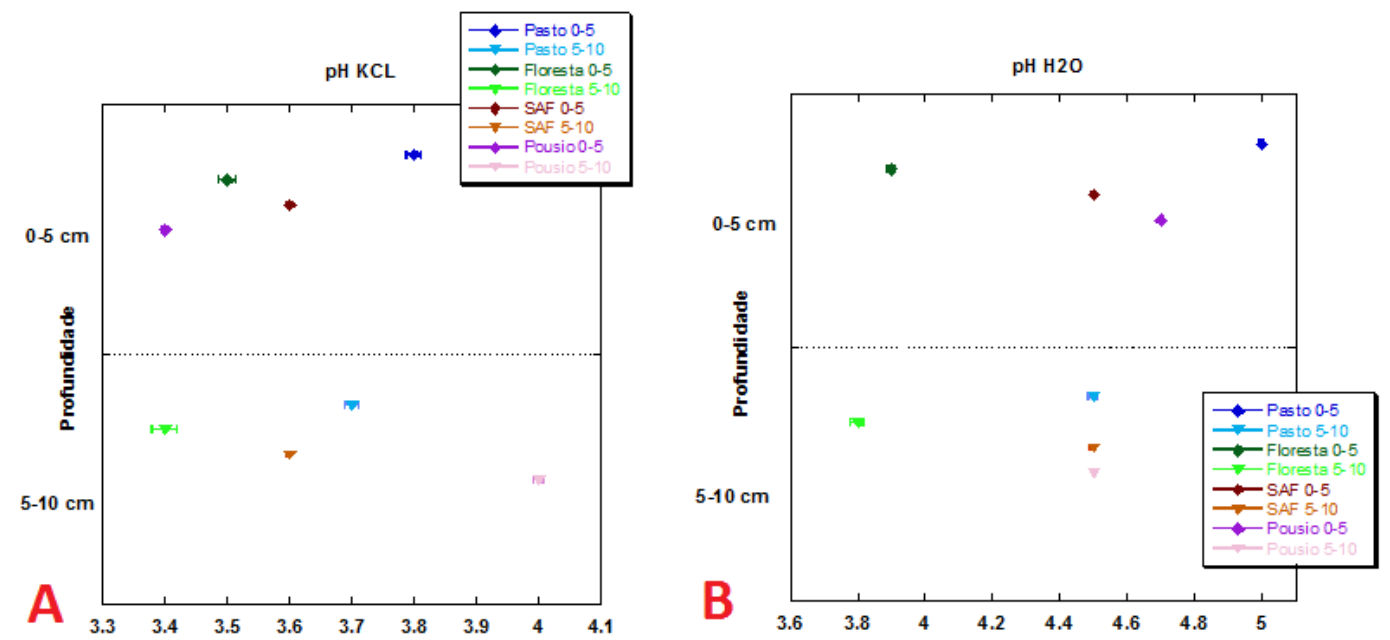

Figura 5: Valores de potencial de Hidrogênio em solução de $\mathrm{KCl}$ (A) e em solução com água (B) nos distintos sistemas e profundidades.

O $\Delta \mathrm{pH}$ (Figura 6) apresenta valores positivos. De acordo com Prado, (1991) o $\Delta \mathrm{pH}$ positivo significa que o solo possui predominância de carga positiva e, consequentemente, maior capacidade de reter ânions que cátions. 


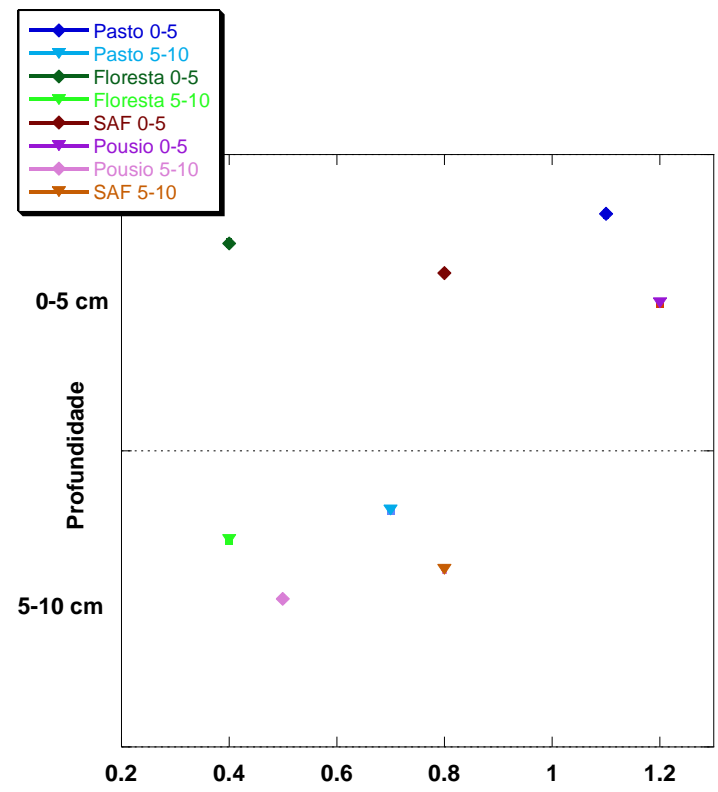

Figura 6: Valores de $\Delta \mathrm{pH}$ nos distintos sistemas e profundidades.

O SAF apresenta os maiores percentuais de Carbono (C) tanto em 0-5 cm quanto em 5-10 cm (1,26\% e 1,04\%). Neste sistema uma das práticas agroecológicas consiste em deixar a vegetação que foi podada sobre o solo, para a entrada de luz, a fim de formar uma proteção natural ao solo do efeito dos processos de escoamento superficial e erosão. Essa técnica proporciona ao solo outro beneficio que é a incorporação de carbono orgânico. Nos primeiros $5 \mathrm{~cm}$ do solo, o Pasto possui $0,86 \%$ de $\mathrm{C}$, contra $0,83 \%$ do Pousio e $0,72 \%$ da Floresta. De acordo com Resende (1997), as gramíneas possuem maior capacidade de incorporar C e matéria orgânica ao solo. Assim, com o aumento da profundidade, os valores de carbono orgânico no solo em 5-10 cm sob o Pasto declinam para $0,55 \%$, em contrapartida com os $0,78 \%$ da Floresta e $0,95 \%$ do Pousio (Figura 7). Por ser um ambiente extremamente arenoso, o aumento dos valores de carbono orgânico no Pousio pode estar atrelado à sua translocação para maiores profundidades através dos poros. 


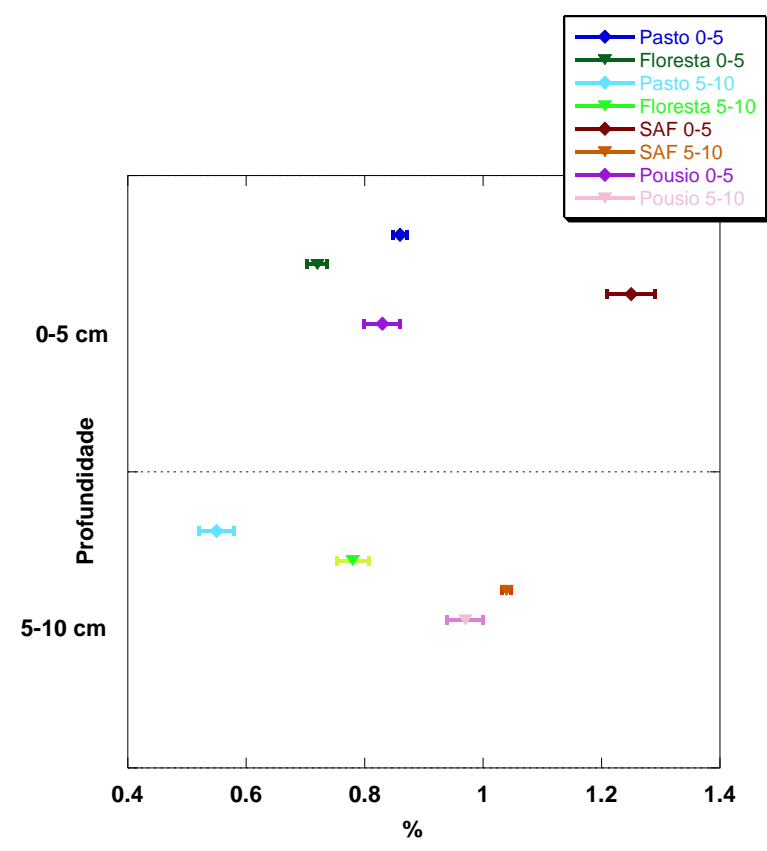

Figura 7: Valores de carbono orgânico nos distintos ambientes e profundidades.

\section{5 - Considerações Finais}

A partir das análises químicas, físicas e mineralógicas realizadas pode-se notar que a cobertura vegetal e o uso do solo implicam diretamente em suas propriedades e qualidade. Os resultados obtidos no Pasto mostram que este sistema apresenta características que podem dificultar a infiltração e a percolação da água no solo, sendo mais suscetível aos processos hidroerosivos, em comparação com os demais ambientes estudados. Evidenciando assim, que por fazer parte de uma Área de Proteção Ambiental, este uso não é o mais adequado, até mesmo porque por estar localizado em uma área montanhosa sob intenso regime pluviométricos, o escoamento superficial tende a ser maior do que o processo de infiltração.

Entende-se que o Pousio vem passando por uma lenta e gradual regeneração, que já apresenta respostas em 0-5 cm, porém menores em 5-10 $\mathrm{cm}$. Os resultados encontrados na Floresta revelam que a mesma está em processo de desenvolvimento. Já o SAF apresenta resultados interessantes indicando que dentro de uma APA, o consórcio entre espécies nativas e cultivos agrícolas, com o auxílio de técnicas agroecológicas, pode representar uma das melhores alternativas para a agricultura familiar. Principalmente pelo fato de minimizar o impacto da produção sobre o solo. Tais resultados derivam das técnicas agroecológicas aplicadas, o que representa o aumento da qualidade ambiental e qualidade de vida, proporcionando a produção de uma paisagem mais sustentável elaborada a partir de intervenções bem planejadas do homem na natureza no que diz respeito às características geográficas, ecológicas e históricas do lugar. 


\section{Referências Bibliográficas}

BERTOLINO, A.V.F.A.; BERTOLINO, L.C. Agricultura migratória e seus efeitos sobre o solo. In: CARNEIRO, M.J. et al. Agricultores e Territórios - práticas e saberes. Rio de Janeiro: Trasso Comunicação Ltda, 2010.

BRASIL. Lei nº 6.902 de 27 de abril de1981.

CANDiOtTO, L. Z. P.; CARRIJO, B. R.; OliVEIRA, J. A. A Agroecologia e as agroflorestas no contexto da agricultura sustentável. In: ALVES, A. F; CARRIJO, B. R; CANDIOTTO, L. Z. P. Desenvolvimento Territorial e Agroecologia. São Paulo: Popular, 2008.

CASTRO, C. M.; PEIXOTO, M. N. O. P.; RIO, G. A. P Riscos Ambientais e Geografia: Conceituações, Abordagens e Escalas. Anuário do Instituto de Geociências - UFRJ. Vol. 28-2/ p. 11-30, 2005.

CASTRO, O. M.; LOMBARDI NETO, F.; QUAGGIO, J. A.; MARIA, I. C.; VIEIRA, S. R. \& DECHEN, S. C. F. Perdas por erosão de nutrientes vegetais na sucessão soja/trigo em diferentes sistemas de manejo. Revista Brasileira de Ciência do Solo, 10: 181-308, 1986.

DANTAS, M.E. Geomorfologia do estado do Rio de Janeiro. Projeto Rio de Janeiro, Brasília, CPRM, 2000.

EMBRAPA. Amazônia Ocidental, Manaus, AM Brazil. 2009. LIMA, H. N. gênese, química, mineralogia e micromorfologia de solos da Amazônia ocidental. Viçosa, 2001.

EMBRAPA. Manual de métodos de análises de solos. Centro Nacional de Pesquisa de Solos (Rio de Janeiro, RJ). Rio de Janeiro, 1999, 370p.

GLIESSMAN, S. R. Agroecologia, processos ecológicos em agriculturas sustentáveis. UFRGS: Porto Alegre, 2001.

GOMES, I. S. L. Qualidade do solo sob uso Agroflorestal em Lumiar, Nova Friburgo-RJ. (Monografia) São Gonçalo: DEGEO - UERJ/FFP, 2009. 48p.

IBGE - Instituto Brasileiro de Geografia e Estatística. Censo demográfico das cidades. Rio de Janeiro, 2010.

INEA - Instituto Estadual do Ambiente. Plano de Manejo da Área de Proteção ambiental do Macaé de Cima. Rio de Janeiro, 2010.

KIEHL, E. J. Manual de Edafologia: relações solo-planta. São Paulo: Ceres, 1979. 262p.

LESSA, G. L. Sistemas Agroflorestais: Uma proposta para a produção da paisagem sustentável: Estação experimental do sítio Abaetetuba, Toca da Onça, Lumiar - Nova Friburgo - RJ. (Dissertação) Rio de Janeiro: Departamento de Geografia - PUC, 2013. 167p.

MIRANDA, J. P. L. de. Influência do Manejo nas Propriedades Físicas do Solo em Ambiente serrano: Paty do AlferesRJ. Rio de Janeiro: Universidade Federal do Rio de Janeiro / Departamento de Geografia. Monografia. 81 p. 2004.

OLIVEIRA, L. B. D. e PAULA, J. L. D. Determinação da umidade a 1/10 de atmosfera na terra fina pela "mesa de tensão”. EMBRAPA. Rio de Janeiro, 1983.

PRADO, H. Manejo dos solos: descrição pedológica e suas implicações. Campinas: Nobel, 1991.

RESENDE, M. et al. Pedologia: base para distinção de ambientes. 2 ed: Viçosa: NEPUT, 1997.

SALOMÃO, F. X. T. Controle e prevenção dos processos erosivos. In GUERRA, A. J. T.; SILVA, A. S.; BOTELHO, R. G. M. (Organizadores). Erosão e Conservação dos Solos: Conceitos, Temas e Aplicações. $6^{\text {a }}$ Ed. Rio de Janeiro: Bertrand Brasil, 2010. 339p.

SILVA, A. S. Análise Morfológica de solos e erosão. In GUERRA, A. J. T.; SILVA, A. S.; BOTELHO, R. G. M. (Organizadores). Erosão e Conservação dos Solos: Conceitos, Temas e Aplicações. $6^{\text {a }}$ Ed. Rio de Janeiro: Bertrand Brasil, 2010. 339p.

\section{Agradecimentos}




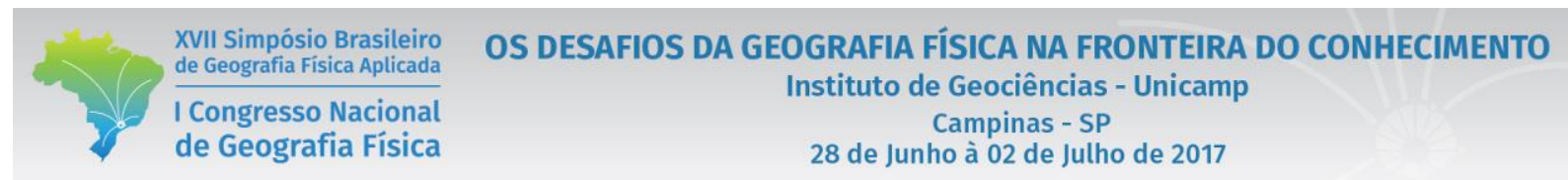

À Fundação Carlos Chagas Filho de Amparo à Pesquisa do Estado do Rio de Janeiro (FAPERJ) pelo financiamento do projeto; $n^{\circ}$ : E-26/111.330/2013 Ao CETREINA por conceder a bolsa para sua elaboração; A toda equipe do Laboratório de Geociências da UERJ/FFP. 